\title{
Probability of death - a guesstimate or an estimate? Recommendation for a more accurate prediction
}

\author{
Perera Jean ${ }^{1 *}$, SenanayakeSMHMK ${ }^{2}$, Appuhamy $\mathrm{P}^{1}$, Hulathduwa $\mathrm{S}^{3}$ \\ ${ }^{1}$ Department of Forensic Medicine, Faculty of Medicine, Colombo, ${ }^{2}$ Institute of Legal Medicine and \\ Toxicology, Colombo, ${ }^{3}$ Department of Forensic Medicine, Faculty of Medical Sciences, Sri Jayawardenapura.
}

*Corresponding author: Tel-0094-77-676-5983, e mail: pererajean32@yahoomail.com

MLJSL.Vol 2. No 1. March. pp 11-14

\begin{abstract}
Introduction

The estimation of the probability of death in an injured victim is a crucial duty of the judicial medical officer in Sri Lanka. Several instruments can be used to approximately predict the probability of death/or survival. To the authors' knowledge, so far no instrument has been used or proposed to predict the probability of death for medico-legal purposes in Sri Lanka. As such there is low inter - rater reliability with possible confusion in a criminal trial. We propose that it is the need of the hour to use such instruments in view of the current controversies around the concept "endangering life". These instruments can also be used to categorize injuries as "fatal in the ordinary course of nature", which are terminology used in criminal trials to categorise the severity of injuries following trauma in Sri Lanka.
\end{abstract}

\section{Description}

The simplest instrument, Abbreviated injury scale (AIS), an anatomical scoring system ranks each injury individually from 01 to 06 . Using the AIS, Injury severity score (ISS)which takes multiple injuries into consideration is calculated which predicts the probability of death. The Revised trauma scale (RTS)is a physiologic scoring system which has a high inter - rater reliability and demonstrated accuracy. The Trauma score - Injury Severity Score (TRISS) determines the probability of survival of a patient with a formula using both ISS and RTS.

\section{Conclusion and recommendation}

Four injury scales/scores would be described with outlines of their usefulness and limitations. The predictive value of each code can be identified by performing multi centre studies to identify which code was more accurate in predicting the probability of death for trauma victims. This would ensure uniform expression of opinions regarding the percentage probability of death; an opinion crucial to express whether an injury is endangering life or fatal in the ordinary course of nature.

Key words: endangering life, probability of death, injury severity score, estimate 


\section{Introduction}

The estimation of the probability of death in an injured victim is a crucial duty of the Judicial Medical Officer (JMO) in Sri Lanka. After examination of survivors of violence the JMO is expected to categorise each injury for legal purposes, depending on their severity and other factors. The nature of the offence and the severity of punishment for the accused in cases of assault may depend on this categorisation. If there is an existent threat to the life of the patient, an injury is categorized as "endangering life". An injury is designated as "fatal in the ordinary course of nature", if it causes death in the absence of prompt and proper medical attention. According to section 294 of the Sri Lanka Penal code "culpable homicide is murder if it is done with the intention of causing bodily injury to any person, and the bodily injury intended to be inflicted is sufficient in the ordinary course of nature to cause death". Thus the JMO has to give an opinion whether an injury is "fatal in the ordinary course of nature" or "endangering life" in the columns provided in the medico - legal examination form.

These two opinions are expressed taking into consideration the JMO's knowledge, clinical and medico - legal experience. It has been noted that certain injuries categorized as 'endangering life' by one JMO, may not be designated as endangering life by another. As such there is low inter - rater reliability with possible confusion in a criminal trial where two experts disagree on these technical issues. To the authors' knowledge as of now, no validated instruments are being used nor proposed in Sri Lanka to cateogorise these injuries, nor consensus arrived regarding them. At times these opinions could be a blend of guesswork and an estimate - a guesstimate.

We propose that it is the need of the hour to develop an instrument in view of the current controversies especially around the concept "endangering life". These instruments can also be used to categorise injuries as "fatal in the ordinary course of nature" , "likely to cause death", and "unsurvivable" or "necessarily fatal" - all legal concepts needing medical expertise. In this paper the injury scales and scores that can be used to develop an instrument will be elaborated quoting examples.

\section{Description}

In clinical practice the probability of death and probability of survival are assessed in triage especially in disaster situations using several scores and scales. Triage is the process of classifying patients according to injury severity and determining the priority for further treatment [1].These same scores and scales can be used to quantitatively determine the probability of death for medico legal purposes. The purpose of this paper is to create awareness regarding the scales and scores available to objectively conclude the probability of death.

Several instruments can be used to approximately predict the probability of death and/or survival. More than 50 experts all over the world have got together to calculate the probability of death in a given injury/injuries and devised these instruments. These are termed injury scales/scores.

The simplest instrument designed in 1969 by over 75 experts all over the world and revised six times after research using trauma victims is the Abbreviated injury scale (AIS). This is an anatomical scoring system and ranks each injury individually from 01 to 06,01 being minor, 02 moderate, 03 serious, 04 severe, 05 being critical and 06 unsurvivable (Table 01). Unsurvivable is a more appropriate medical term for what is termed as 'necessarily fatal' in legal parlance in Sri Lanka. AIS comprises of a dictionary with a section for each anatomical area such as the head. AIS is useful in predicting the severity of each independent injury and remains one of the most commonly used injury coding systems [2]. 
Table 01. Abbreviated injury score - AIS

$\begin{array}{ll}01 & \text { Minor } \\ 02 & \text { Moderate } \\ 03 & \text { Serious } \\ 04 & \text { Severe } \\ 05 & \text { being critical } \\ 06 & \text { Unsurvivable }\end{array}$

Examples of AIS and their corresponding probability of death is given below

\begin{tabular}{|c|c|c|}
\hline $\begin{array}{l}\text { AIS(severity } \\
\text { score) }\end{array}$ & Example & $\begin{array}{l}\text { \%probability } \\
\text { of death(POD) }\end{array}$ \\
\hline 1 & $\begin{array}{l}\text { superficial } \\
\text { laceration }\end{array}$ & 0 \\
\hline 2 & $\begin{array}{l}\text { fractured } \\
\text { sternum }\end{array}$ & $1-2$ \\
\hline 3 & $\begin{array}{l}\text { open fracture } \\
\text { humerus }\end{array}$ & $8-10$ \\
\hline 4 & $\begin{array}{l}\text { perforated } \\
\text { trachea }\end{array}$ & 50 \\
\hline 5 & $\begin{array}{l}\text { ruptured liver } \\
\text { with tissue loss }\end{array}$ & 50 \\
\hline 6 & $\begin{array}{l}\text { total severance } \\
\text { of aorta }\end{array}$ & 100 \\
\hline
\end{tabular}

The disadvantage of AIS when applied to medico - legal practice is that at a given time only a single injury is graded. In routine practice, often injured victims have multiple injuries and the injuries taken together will determine whether or not death will supervene. Therefore, a scale taking multiple injuries in to consideration should be available.

However, in court trials into homicide and attempted homicide, sometimes it is crucial to determine whether a single injury has contributed to death; especially when there are multiple assailants and there is the need to determine the probability of death of a single specific injury. In such cases the AIS alone would be of use.

\section{Injury severity score}

Injury severity score(ISS) [3] which considers the overall injury burden sustained by the patient and predicts the probability of death, is calculated using the AIS using 06 main body regions; head and neck, face, chest, abdomen, extremities (including pelvis), external. The ISS is the sum of the squares of the highest AIS code in each of the three most severely injured body regions. An example is given below.

\begin{tabular}{|ll}
\hline Body region & Abb \\
\hline Head and neck & 4 \\
\hline Face & 2 \\
\hline Thorax & 5 \\
\hline Abdomen & 1 \\
\hline Lower & 3 \\
limb(extremities) & \\
\hline Skin(external) & 1 \\
\hline
\end{tabular}

The bold numerals represent the three most severe injuries in a patient. The square of the AIS of these three injuries are taken to calculate the ISS. ISS $=(5 \times 5)+(4 \times 4)+(3 \times 3)=50$

The ISS range is $0-75$ where a score of 75 is unsurvivable. An AIS of $6=$ ISS score of 75 or unsurvivable. An ISS more than 15 has been designated as a major trauma [4]. An ISS less than 9 is a minor injury, between $9-16$ moderate, $16-25$ serious, and over 25 severe.

The Revised trauma score (RTS)is a physiologic scoring system based on the blood pressure(BP), Glasgow coma scale(GCS) and the respiratory rate(RR), and has a high inter - rater reliability and demonstrated accuracy in predicting death. Furthermore current revisions accommodate correction for low income countries, thereby it can be applied to Sri Lanka if studies are conducted to check its validity to predict death. Although calculating the score seems complex, simple computer programs are available to help. The revised trauma score ranges from 0 (dead) to 7.84 (normal). The formula for RTS $=0.9368 \mathrm{GCS}+$ 0.7326 SBP $+0.2908 \mathrm{RR}$, thus it is heavily weighted towards the Glasgow Coma Scale to compensate for major head injury without multisystem injury or major physiological changes. The RTS (Table 02)is said to correlate well with the probability of survival [5]. In fact it has been suggested as a reliable indicator for distinguishing life threatening injuries [6]. 
Survival Probability by Revised Trauma Score

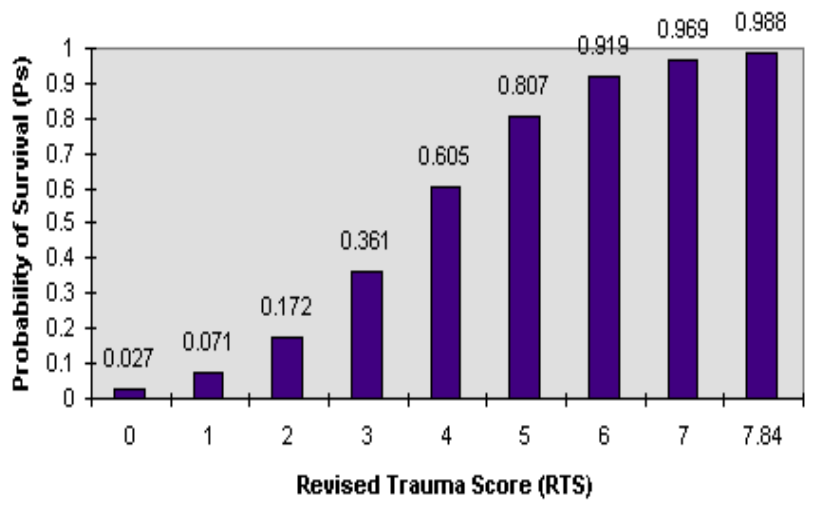

(Table 02)

The TRISS Calculator - Trauma - Injury Severity Score

The Trauma score - Injury Severity Score (TRISS) determines the probability of survival of a patient with a formula using ISS and RTS and patient's age [7].

\section{Conclusion and recommendation}

Four injury scales/scores which can be used in order to ascertain the probability of death or survival have been defined with outlines of their usefulness and limitations. The authors recommend a multi centre research through the College of Forensic Pathologists of Sri Lanka to ascertain the most appropriate score or scale for Sri Lanka. If the available scores are not valid for the above purpose then an instrument could be developed based on the above scores and a consensus should be reached. Thereafter its usage can be recommended through the college. This will lead to uniformity in the expression of opinions regarding the percentage probability of death; an opinion crucial to express whether an injury is endangering life or fatal in the ordinary course of nature.

\section{References}

1. ACS-COT: Resources for optimal care of the injured patient: Chicago: American College of Surgeons; 2006.available at www.ncbi.nlm.nih.gov/pubmed/22237112

2. William $C$ Wilson, Christophe M Grandy, David B Hoyt,Trauma and critical care, First edition 2007 Informa Healthcare USA p. 432.

3. Baker SP et al, The Injury Severity Score: a method for describing patients with multiple injuries and evaluating emergency care, J Trauma, Vol.14,1974:187-196.

4. Lossius HM, Rehn M, Tjosevik KE, Eken T, Calculating trauma triage precision: effects of different definitions of major trauma. Journal of Trauma Management \& Outcomes, 6:9

5. WWW.TRAUMA.ORG//archive/scores/rts.ht $\mathrm{ml}$

6. Boyd CR, Tolson MA, Copes WS, Evaluating Trauma Care: The TRISS Method. J Trauma Vol. 27, 1987:370-378.

7. Bilgin N.G., Mert E., ÇamdevirenH., The usefulness of trauma scores in determining the life threatening condition of trauma victims for writing medical-legal reports, Emerg Med J 2005; Vol.22 issue 11:783-787.

\section{Contribution of authors}

Design to the study - JP

Analysis of the data- JP, KS

Interpretation of the results- JP, KS

Writing the manuscript $-J P, K S$

Revising the manuscript- JP, KS, PA, SH 